\title{
Dynamic assessment effect on speaking performance of Indonesian EFL learners
}

Fahmi, Bambang Widi Pratolo, Nurul Amalia Zahruni

Master of English Language Education, Universitas Ahmad Dahlan, Indonesia

\begin{abstract}
Article Info
Article history:

Received Jan 6, 2020

Revised May 15, 2020

Accepted Jul 16, 2020

\section{Keywords:}

Dynamic assessment Indonesian EFL learners Speaking performance

ABSTRACT

The research concerned the application of Dynamic Assessment (DA) in English Language Teaching (ELT) which based on Vygotsky's theory, namely Zone of Proximal Development (ZPD). The research was meant to investigate the effect of DA in improving teaching and learning speaking in Indonesia especially English as a Foreign Language (EFL) learners in university. The research was conducted using a qualitative method by involving four Indonesian university learners in the first semester. The participants received the same treatments through pre-test and selfreflection, feedback and knowledge expansion, post-test and self-reflection, post-feedback, and semi-structured interviews. The instruments were used to analyze the learners' non-fluency and mastery problem. The analysis showed that the learners' speaking performance was improved after experiencing DA sessions. The results of the test and self-reflection showed significant improvement in their speaking. The finding showed some positive effects of DA on EFL learners' speaking performance. In interviews, learners showed positive experiences and attitude toward DA since it served them a comfortable, structured, practical, and meaningful platform to recognize their speaking behavior, weaknesses, strength, and needs. Furthermore, it also helped them to get the objective feedbacks with less anxiety. The researchers conclude that DA can be applied as a primary alternative assessment in English speaking practices.
\end{abstract}

This is an open access article under the CC BY-SA license.

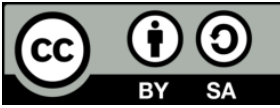

\section{Corresponding Author:}

Bambang Widi Pratolo,

Master of English Language Education,

Universitas Ahmad Dahlan,

Jl. Pramuka 42, Sidikan, Umbulharjo, Yogyakarta, Indonesia.

Email: bambang.pratolo@pbi.uad.ac.id

\section{INTRODUCTION}

In Indonesian educational system, it is common for an educator to implement assessment with an evaluator-centred approach. Meanwhile, most of Indonesian students still assume that English is a difficult language to learn. The evidence of learner's difficulty in learning English can be seen in these phenomena. Most of Indonesian students cannot speak English even though their age has reached over 17 years old and have learned English for over six years [1]. Even, the students who are already in the third or fourth semesters in a university still strunggle to speak English. It means that there is a severe problem with the teaching and learning process in Indonesia. Even, Zhou as cited in Ramdani and Rahmat [2] revealed that these phenomena were also experienced by some other countries in Asia that university learners were unable to speak appropriately in English. Regarding this matter, one of the alternatives that can be carried out for monitoring and giving assistance is through assessment. Cowen [3] believed that assessment is an essential way to recognize the uncertainty and the gap between what students learn and what the evaluator teach in 
a particular topic or material. A good design of assessment should find the core of learners' difficulties in which the assessment makes the learners more comfortable in learning, honest with their own weakneses, to feel better in delivering their confusion about the material and make them more enthusiastic in learning.

Furthermore, it is also a common thing to see that most of Indonesian lecturers use traditional assessment as a standard method to assess their students' speaking ability. Some previous researchers [4] noted that learners who perform poorly in traditional assessments tend to be less competent in dealing with their difficulties in learning. As a result, the learners who are unable to pass the test in an English course have to repeat the course without knowing how to improve their poor performance and may eventually be trapped in that course. These learners need assistance in finding their way out of the trap; otherwise, they may lose their self-confidence or even internalize negative perceptions toward their English ability. Thus, it is unfair to standardize the learners' ability only based on score in a test and assume their score as their final achievement. Whereas, learning is an on-going process.

Assessing Indonesian EFL learners who are from different language and cultural backgrounds can be a complicated task for the evaluators. One of the alternatives that can be applied to measure these differences in testing is Dynamic Assessment (DA). Moreover, the procedure of DA emphasizes the process of learning, the interest of learners, and the experiences of learners along the process of DA sessions. The essential thing is that the learners feel not being judged by scores or final decision of a test during their on-going development. Regarding this matter, Narciss and Huth cited in Hasim, Di, and Barnard [5] suggested that feedback should not mostly talk about correct or incorrect answer, but rather mostly talks about suggestions, motivations, and strategies based on learners' interests and experiences in improving ability. Teo [6] also emphasized that testing is just a tool and score is just a measure which lead to judging and labeling. Whereas, in DA, the learners are oriented to recognize their mistakes or weaknessess and solve it through their inner voice and creativity in the mediation process. These ways surely make learning and teaching process more oriented and flow naturally.

In DA practices, learners who would potentially get stuck in the test can be equipped with direct instruction, guided practice, and practical strategies to cope with their difficulties while taking the test. Regarding this cooperative and responsive orientation, DA has been proved to be an interactive and useful tool for working with such learners [7,8]. The participants who were the subject in this study were Indonesian EFL learners with low English speaking performance whose previous speaking performance was assessed using traditional assessment in the classroom. This study is aimed to investigate and evaluate the potential effect of DA on Indonesian EFL learners and help these learners in improving their English speaking skills. Regarding DA's practice in Indonesian classroom, it is essential to say that the implementation of DA is very uncommon in Indonesia.

Assessment in learning regards the learners with different learning strategies and put them in the unique individual who tries to make progress in acquiring knowledge and skill. The debate and discussion over various assessment techniques appeared at the core of teaching aims and the demanded outcomes [9]. Assessment transforms its implementation from traditional testing method to more authentic testing method and holistically presented by the active learners' participation, peers, and evaluators. This also encouraged learners to come nearer towards real-current situation tasks in complicated real-life [10]. National Research Council [11] stated that learning and assessment are assumed as parts of each side of the same coin in its relationship. As a consequent, when learning is based on the context of actual life in its practice, the assessment also should rely on the real context, actual strategies and technique. Therefore, the most important in assessment is the fairness in techniques, times, and contexts, then the validity and reliability more guaranteed.

Douchy [12] stated that any assessment instrument need pay attention on its implementation that convey knowledge to actual or real contexts of life. Teachers should stay aware of what learners do and need. An assessment should be put in the vital part of works or tasks as learners need to find out the changes in their progress and learning experiences. Moreover, individual judgement can be a very crucial issue found in speaking assessment [13]. Therefore, a proper assessment should fully pay attention to the quality of feedback which concerns the intensive engagement in both, during learning-teaching activities and after learning-teaching activities. Feedback should give positive reflection for both the learners and the lecturers in which the learners feel comfortable or not feel being judged, and the lecturers gain a deeper understanding on their learners' problem. In this way, the learners take more advantages in receiving the feedback. DA highly concern on the feedback and treatment of how the learner should develop their ability in process instead of concerning their score.

Dynamic Assessment has a uniqueness to look not only backward, but also forward [14] in a process-oriented approach of assessment which is occasionally known as learning potential assessment [15]. Its goal is to bring about improved performance through the examiner's assistance provision (or mediation) during the test. It is claimed by DA proponents that the learners' responsiveness to the mediation is assign of 
what they are going to be able to do as individuals in guidance to draw learner's conscious attention to the test task faced individually [16, 17]. In this way, the learner is empowered to enthusiastically interact and collaborate with the examiner as the mediator along the test task course. Besides, DA is also applied to cause or boost a positive change in the learners by reorienting and redirecting their ability to learn during the implementation of the task. As the integration of assessment and instruction, it serves relevant information about the learners' underlying capability and ability to enable evaluators to comprehend their learners who lack the performance and prepare a plan to solve those aspects in the learners' range and scope [18, 19].

Walqui \& Linquanti [20] and Nazari [21] had a view that DA has been commonly applied in educational psychology and second language pedagogy to substitute or complete what traditional assessment lacks. DA is more focused on the empowerment of the individual to promote the engagement of learners in the assessment process. Meanwhile, traditional assessment more likely prioritizes test scores consistency because its purpose is a summative product which was used to compare among individuals for categorization or classification purpose. Thus, DA provides a high assessment qualification since it serves the investigation on learners' learning process and uniqueness basis as an individual. Table 1 shows the comparison of traditional assessment and dynamic assessment.

Table 1. The comparison of traditional assessment and dynamic assessment

\begin{tabular}{lll}
\hline \multicolumn{1}{c}{ Criteria } & \multicolumn{1}{c}{ Traditional assessment } & \multicolumn{1}{c}{ Dynamic assessment } \\
\hline Participation & Passive participants & Active participants \\
Focus & On product & On process \\
Examining process & $\begin{array}{l}\text { De-contextualized, objective, } \\
\text { and standardized }\end{array}$ & Contextualized, interactive, and individualized/responsive \\
Role of examiner & Examiner observes & Examiner Participates \\
Orientation & Retrospective approach & Prospective approach \\
Interpretation of results & Limit on performance & Learning potential (obstacles and way to overcome them) \\
\hline
\end{tabular}

Van der Veen, Dobber, and van Oers [24] found that DA is a potential assessment and very encouraged to be applied in teaching and learning practices. However, this assessment has not been applied or practiced in many teaching and learning process yet. This issue was emerged because there are some difficulties in transferring or changing the psycholinguistic context of DA into the classroom context. Finally, there is a worry that the DA's procedure may challenge the reliability and fairness of the test [23]. In addition, it had been argued that these problems refer only to the question of where the priority should be placed [25-27]. In exclusive way, Murphy believed that DA supporters emphasize its focus on all individual itself rather than the the scores of the test [28]. Meanwhile, Launchan [29] also stated that, in spite of their reliability, a standardized test scores may not show valuable information about the examinees' real potential DA will be accurate when the examiners objective is mainly prioritizing a focus to encourage learning ability of the examinees rather than reported scores based-decision or based on the score consideration.

Underhill [30] had pointed out that speaking tests should offer examinees a chance to behave as individuals. Meanwhile, the previous researcher had identified the features that influence individuals' language ability in their test performance. The first features are special needs that require special measurements and accommodations for examinees' disabilities. The second set includes examinees' interests, emotional stage, motivation, learning strategies, and learning styles. The third set consists of external influences like former education, examination preparedness, the experience (examination and communication), and other similar external influences that can be significant effects on examinees' ability to speak. DA is equipped to support all three sets of features [31], and thus, can be integrated into speaking tests in order to optimize the speaking skills of the examinees.

The previous studies promote several applications of DA in a particular context with a particular aim and with the different methodology of collecting and analyzing the data. Therefore, the researchers conducted different analysis on this technique as the development of current needs in the teaching and learning process. The related studies are reviewed as follows: Khoshima and Farokhipours [32] conducted research related to DA technique to five learners as participants who were selected randomly in the course of intermediate language learning at Chabahar Maritim University. The research used a mixed method to gain the data, and it was aimed to explore the mediatory strategies of interactionist and interventionist and the effect of different models of DA on promoting the speaking competence of Iranian EFL learners. Its result showed that the learners' scores improved on post test and so in the session of interventionist mediatory. Its finding showed that the learners were assissted by interactionist DA in term of performing speaking and overcoming speaking problems through teacher interaction. 
Another study related to DA technique was also conducted by previous researchers, which involving two Iranian learners of state university who never take any private or specific English Classes. The speaking tasks were conducted using six pictures as a set of story scene in several DA sessions and with Novel as the final task. The research found that the development of learners' movement was getting closer or turn into self-regulation and so the cognition was. Meanwhile, the unstructured interview was analyzed thematically, and its results showed that the learners feel satisfied with DA [33].

Meanwhile, Karimi and Shafiee [34] investigated 42 EFL Teachers in ELT related courses who held BA degrees (22 teachers) and MA degrees (20 teachers) in terms of their perception toward DA. The research is intended to report the results of the thematic analysis on the perception of Iranian EFL teachers (BA and MA degrees) toward DA, which is related to their length of service and academic degree. The result from recorded interviews showed the four major themes of concerns. The research found that the concerns and perceptions of participants' patterns had significant differences.

Therefore, the researchers applied DA in Indonesian context since Indonesian educational assessment need some improvements in term of its implementation toward EFL learners. The originality value of this study is identifying the matter of non-fluency on the speaking performance based on EFL learners' self-feedbacks, self-correction, and self evaluation in Indonesian context.

\section{RESEARCH METHOD}

\subsection{Participants}

The researchers investigated four EFL learners as participants who are selected through purposive sampling. The researcher also gave an initial to each participant for privacy protection. The participants' parents are not an English teacher or lecturer. The participants are the first-semester of university learners, and all participants are the same class of English education department in a private university in Yogyakarta.

\subsection{Instruments}

In this research, the researchers applied descriptive-qualitative research instruments for collecting the data [35]. Qualitative instruments consisted of stimulating information, pretest, post-test, feedback and knowledge expansion, and semi-structured interviews. Meanwhile the data was in the forms of deep elaboration or discription rather than number [36]. Participants' speaking performance in DA sessions was video-recorded (with participant's permission). Each participant watched the video of themselves and immediately did the task. So, the participants could follow their thinking process and apply it in verbal. Pre-test and post-test were employed not for scoring. But, to obtain the speaking records and speaking transcriptions to be analyzed in the self-correction and self-feed back sessions, and also as the sources of mediator's analysis and feedback toward the learners. The semi-structured interviews are employed to gather further information based on their verbal self-report. The participants were asked to have self-evaluation as the supporting informations to be inserted or cross-referenced with other data in order to get the rich and valid data.

\subsection{Procedures}

The researchers gave a speaking test to the participants for measuring their current performance in speaking. Then, the researchers classified the error and non-fluency of their works on the speaking test. The next step, the researchers recognized participant's difficulties by asking them to have a self-evaluation on their insight problem, gaps, or difficulties after the tests. Meanwhile, the participants' attitude toward DA was measured through individual oral interviews. The semi-structured interviews was employed and recorded for data collection. The researchers classified the participants' data through coding. The results of the interviews showed apparent aspects concerning participants' difficulties, non-fluency, needs, ability, and the insight of their attitude toward the DA itself. Then, the researchers provided speaking encouragement during DA through knowledge expansion and feedback regarding learner's behavior, routine, and other specific feature or characteristics that influence their development in speaking performance. Before training them for the speaking task in DA sessions, they were provided with information about DA, the objectives, processes and time frame of the research, and they already had well-prepared for the interviews and open-minded to cooperate with researchers.

\subsection{Data analysis}

The qualitative data which had been collected were analyzed and categorized. The participants were informed that all parts of speaking pre-test and post-test in this research were not for evaluative purposes. The criteria of non-fluency are: filled pause, repetition, retraced false start, and interjection. The data from participants' non-fluency, self-reflection, attitude while accepting knowledge expansion, and feedback are 
analyzed, coded, and categorized to recognize participants' strengths, weaknesses, and needs in speaking skill. Besides, the data of participants' interviews and further self-reflections are also coded and categorized to get a deeper description on participant's change, motivation, effort, and development in their performance in speaking skills. The selective and open coding [37] was employed to recognize the key points of participants' language, reason, dificultiess, routine, and efforts.

\section{RESULTS AND DISCUSSION}

\subsection{To what extent does dynamic assessment encourage Indonesian EFL learners to improve their speaking performance?}

The qualitative data showed some improvements in participant's speaking performances during DA sessions. The participants concern more on the matter of their non-fluency. The individual's confidence in speaking increased significantly and they got used to encourage themselves to speak openly based on their own thoughts. Furthermore, the participants believed that DA encouraged them to be more careful in every step of treatment and assessment during DA especially in the matters of repetitions, filled, retraced false start, and interjection. These results could be seen in following quotation:

[N] I feel my performance in speaking get better than previously since the session give me some chances to fix my non-fluency in speaking. Right now, I know how to analyse my mistakes and to change my ways in performing speaking later

[D] I know my mistake now; I do a lot of mistake such as filled and repetition of particular word during performing my English speaking

[I] During the self-correction and feedback session, it makes me more understand how to use coherence between sentences in my speaking

In addition, a participant also stated that DA contributes to their perception and believed that speaking English could be improved easily if there was immediate-feedback on what they had done and treated consistently. This perception could be seen as following quotation:

\section{[I] I understand faster since I have some chances to correct my mistakes directly and get a lot of feedbacks related to what I should improve}

Based on the above quotation, it was also in line with Nazari [38] who said that student should feel free in making mistakes and practicing their oral performaces, then their mistakes should be corrected immediately so that it will not be an obstacle for learners'potential to understand and be understood. Furthermore, previous study also had a view that learner's mistakes can be a valid confirmation for the essessor or evaluator on which concepts or aspects the learners need to understand [39]. The evidences which proved participants' improvement in speaking was obtained from their non-fluency analysis as viewed in the result of pre-test and post-test, self-correction and the correction from mediator. The treatments were given in the forms of feedback on the correction, feedback on the test, feedback on further improvement, selfreflection, motivation, and knowledge expansion. Haywood and Lidz [23] believed that the essence of DA's characteristics is its fuction as a responsive or collaborative model in which the assessor provides motivations, feedback, and guidance as an effort to obtain the finest achievement. The participants' performance was improved after experiencing DA session as can be seen in Table 2.

The analysis on non-fluency of speaking performance across the pre-test and post-test's result showed a noticeable improvement in the participants' performance (Table 2). Table 2 showed that there was significant difference in speaking non-fluency of all participants' performance. At the post-test, the first participant in the table showed there was six times difference in non-fluency and without doing any interjection at all. Moreover, repetition and retraced false start were also the same. Meanwhile, the second, third, and fourth participants showed more significant non-fluency's difference. For example, filled pause which had been made by the second participant had dropped to fifteen times, the third participant dropped to to sixty times and the last participant had dropped to eleven times. Furthermore, the highest repetition difference was shown by the third participant with the difference thirty-three times. All of these data and analysis showed the significant improvement of participants speaking performance which was encouraged through DA as seen in Table 2 (the difference of participants' non-fluency). 
Table 2. Non-fluency of participants' speaking performance

\begin{tabular}{|c|c|c|c|c|}
\hline Participants & Non-fluency & Syllables, Words, and Phrases which Showed Non-fluency & Pre-Test & Post-Test \\
\hline \multirow{4}{*}{$\mathrm{P} 1: \mathrm{N}$} & Filled pause & eee, eemm & $22 x$ & $16 \mathrm{x}$ \\
\hline & Repetition & not thrifty, better if, what they are need, it is & $6 \mathrm{x}$ & $3 x$ \\
\hline & Retraced false start & $\begin{array}{l}\text { be give-be given, several of them-many of them, all of-their } \\
\text { time, to-or }\end{array}$ & $5 \mathrm{x}$ & $1 \mathrm{x}$ \\
\hline & Interjection & eh & $1 \mathrm{x}$ & $0 \mathrm{x}$ \\
\hline \multirow{4}{*}{ P2: I } & Filled pause & eee, emm, aaa,yeahh & $25 \mathrm{x}$ & $10 \mathrm{x}$ \\
\hline & Repetition & $\begin{array}{l}\text { we have to, we we, in, like, for example, wiil try, with, it } \\
\text { is, online, will get }\end{array}$ & $13 x$ & $12 \mathrm{x}$ \\
\hline & Retraced false start & $\begin{array}{l}\text { have to use-it doesn't matter, without-monday, like-so, have to- } \\
\text { and we, depend on-if evaluator, one their-one hours, of us-for us, } \\
\text { in our-likeparticipants, laptop to-we have, so it is not-but } \\
\text { depend, the evaluator-all evaluator, depend-dependent, will } \\
\text { make-will waste, so-that is-but,is-was, }\end{array}$ & $10 \mathrm{x}$ & $4 \mathrm{x}$ \\
\hline & Interjection & & $0 \mathrm{x}$ & $0 \mathrm{x}$ \\
\hline \multirow[b]{3}{*}{ P3: E } & Filled pause & eee, emm, aaa,yeahh & $82 x$ & $18 \mathrm{x}$ \\
\hline & Repetition & $\begin{array}{l}\text {; when the, will, harmonies, many, there are, to accept, their, i } \\
\text { believe that....... }\end{array}$ & $41 x$ & $8 x$ \\
\hline & Retraced false start & $\begin{array}{l}\text { when they -and they, when the tea-when the student, as rich-rich } \\
\text { people, they are-you wear, when the policy-when the } \\
\text { environments, iam-i, their think-their thinking, investy- } \\
\text { investation, then so-then i, a idea-an idea, not only when they- } \\
\text { not only after, for-from, invest-investation, and a-and the learner, } \\
\text { make-they are made }\end{array}$ & $13 x$ & $2 \mathrm{x}$ \\
\hline \multirow{5}{*}{ P4: D } & Interjection & $\mathrm{eh}$ & $1 \mathrm{x}$ & $0 \mathrm{x}$ \\
\hline & Filled pause & eee, emm, aaa,yeahh & $28 \mathrm{x}$ & $17 x$ \\
\hline & Repetition & and for, & $1 \mathrm{x}$ & $0 \mathrm{x}$ \\
\hline & Retraced false start & $\begin{array}{l}\text { about the uniform-the same uniform, the material-this material, } \\
\text { about-for example, give-for-and, minimalist-minimize, a make-a } \\
\text { good }\end{array}$ & $5 x$ & $2 \mathrm{x}$ \\
\hline & Interjection & ou & $1 \mathrm{x}$ & $0 \mathrm{x}$ \\
\hline
\end{tabular}

In order to conform to the first question, the learners' non-fluency was recognized to encourage learners' awareness in overcoming their weaknesses. Recognizing learners' weaknesses in speaking could be obtained through learners' speech or narration. This was also in line with Ebadi and Asakareh [33] that types and frequency of learners' errors in language were extracted from learners' narration in a test. The researchers provided speaking test through narration in order to make a collaborative talk which make the test more comfortable and directed [40]. In further consequence, learners could be an analyzer for themselves in solving their non-fluency and improving their speaking performances. In this context, learners' potential development was directed at the stage problem-solving in analyzing their non-fluency under field-expert guidance [41], or in collaboration with lectures. As the result, the participants was encouraged to get used to collaborating or interacting. At this situation, the encouragement or assisstance emerged from a comfortable interaction or collaboration between learners and educators [42]. In addition, Brown cited in Nasir, Yusuf, and Wardana [43] pointed out interaction as a platform for exchanging feeling, thoughts or ideas collaboratively among learners or between learners and an educator for creating intensive reciprocal impact in learning and teaching process.

\subsubsection{Participants' self-evaluation on their speaking performance in DA sessions}

Participants' self-evaluation was conducted to increase participants' confidence and to maintain their responsibility toward their speaking performance in comfortable way. In facing pre-test and post-test, participants learnt how to explore their learning style and self-control through some assistance in DA sessions. These matters can be seen in following quotations:

P2: I. After listening the records of my speaking performance in post-test, I thought that my performance at post-test is better than the pre-test records in many ways even though there are still some mistakes I have done.

P1: N. My doubt and nervous decrease and I feel that I can create my own ways to get the better performance later after finding out my mistakes and how to fix it in self-evaluation session.

P2: I. I am aware of my weaknessess in speaking performance after doing self-correction on my speaking performance pre-test records and transcription. I find that I always do 
repetition such as ...like eee..,will get....and will try...... Then, I also find that many mistakes in using conjuction, vocabulary that make me frequently do filled paused such as ...eeee..., ...emm..., and ...aaaa... during pre-test. Right now, I know how to manage or cope with my vital mistakes after finding out the causes of my mistakes through self-correction, selffeedback, and direct feedback ...

The above quotations showed some implications of DA session on the self of participants in performing their speaking ability. This essential thing was inline with Ebadi and Asakareh [33] that inner voice could be developed through assistance during encounter difficult task or experiences a problem. The ability of self-control in analyzing the problem is a product of self-regulation. Self-regulation created learners'awareness to encourage their responsibility toward their own performance. Therefore, the assistance to develop learners' inner voice can be provided through self-evaluation on the purpose of gaining self-regulation.

Meanwhile, during the pre-test and post-test, participants were assisted by researchers to evaluate their own speaking through transcription and their speaking record. The participants were expected to do a reflection of what they were speaking about and the error they had been made. The researchers provided specific instructions for the participants to do self-reflection or self-evaluation. After the participants evaluated themselves, they were immediately asked by researchers to tell what they felt, what they need, what they should do, what their lack, what they were satisfied about regarding the level of the achievement of their speaking performance. In the pre-test, two participants were satisfied since they could recognize their mistakes clearly from their speaking transcription and speaking record provided by researchers.

P4: D. I get a lot of experiences in term of analyzing my own mistakes in performing speaking and know how to correct the mistakes step by step during the session

P1: N. In pre-test I do many mistakes, then after I analyze and correct it by myself through the steps provided, I can minimize the fatal mistakes as can be listened in the post-test records and its transcription... it makes me easily recognized the fatal mistakes of my speaking performance

This way was in line with DA characteristic that the process lead to learners' potential in interaction where the experts in this case the teacher or lecture as a dynamic assessor and learners were enggaged each other in an interaction [44]. The assessors gave instruction on how the learners will perform in particular tasks, how to practice and overcome the difficulties, measure and assisst their own learning progress for solving the same problems. Yanita, Yusuf, and Gani as cited in Nasir, Yusuf and Wardana [43] clearly stated that the quality of interaction between teacher or educator with the learners is one of the signs of the success in teaching.

Meanwhile, the other participants had recognized that they did not really feel satisfied with their mistakes that they found several difficulties such as grammatical error, filled, interjection, and relations among ideas in sentences and paragraphs. They also recognized that they made the same mistake. For example, one of the participants had recognized herself made the same mistake in repetition at several sentences. Meanwhile, the participants who felt confident with her speaking had recognized that her improvement was increased by raising her voice and activate body gesture. The results of self-reflection done by participants made them understand what they lack and what they need for their speaking improvement. Based on the results' statement above, followings are the quotations of participants' self-evaluation regarding their speaking performance (satisfactory of recognizing mistakes and confidence) after reading the transcription and listening to the records of their performance:

P2: I. I automatically know my ability in speaking. Previously, I never checked my mistake in performing speech. This gives me experiences of how to check, fix, and improve my speaking performance.

P3: E. I get many experiences from this. Now, I know how to reflect or introspect myself toward my mistakes in speaking, especially in grammatical error, misuse vocabulary, and repetitions.

P4: D. I never thought that my speaking has a lot of mistakes. I make a lot of mistakes in constructing sentences and using the improper vocabulary based on the context. 


\section{P2: I. I move my hands a lot and sometimes move my body during the speaking test session} because I feel comfortable and it trigger my enthusiasm to speak

The quotations of participants' self-evaluation above illustrated participants' point of view of what they had done in DA sessions. Previously, most participants did not realize which part their weaknesses occur and how to deal with it. However, after having self-evaluation session, participants got a clear description of what their weaknesses are and where their weaknesses specifically occur. Thus, these matters helped them to have self-awareness on their weaknesses. Some participants reported that they could make a reflection from their recognized-weaknesses to anticipate and minimize their mistakes. Meanwhile, another participant reported that DA changed their learning style and strategies for further speaking performance. They also reported that it influenced their speaking especially in recognizing the weaknesses which was not specifically realized along the previous speech. They felt more directed of what weaknesses should be fixed what should be improved, and which strategies should be applied. Regarding learners' weaknessess, the mistakes made by learners suppose to be viewed as a normal process of learning a foreign language, not as something to judge [39].

\subsubsection{Feedback and knowledge expansion on participant's speaking difficulties}

After listening to the self-reflection from the participants, researchers were immediately involved in giving feedback for their problem through reliable sources based on participants speaking non-fluency analysis (shown in Table 2) and from their self-reflection. The feedback was also carried out to recognize the participants' understanding and to find out the easiest and the most effective strategies to improve their speaking performance. Concerning the problem in speaking faced by participants, the feedback made them open-minded on what their lack and what they need for their improvement. The researchers investigated what the participants' say in their inner voice about their speaking performance during DA session. In this way, the participants were fully involved in the process of assessment. Sun and Wen [45] highlighted that the involvement of learners in the process of assessment can increase learners' self-responsibility and autonomy in learning, and it also assist them to analyze language features more deeply. Participants 'involvement in the assessment process in the form of self-reflection and self-feedback not only gave them the opportunity to be enthusiastic, open-minded and comfortable, but also to get an opportunity for the assessor to identify the participants' speaking difficulties in deeper. Regarding feedback, Nazari [38] argued that the implementation of feedback in DA is strongly fair since it provided feedback proportionally or based on participants' need to accomplish their potential. Followings are participants' reports regarding their difficulties in speaking:

\section{P1: N. I often think too much, I am afraid of making any mistake while speaking, especially in constructing sentences.}

P3: E. I always do repetitions and use the double verb. My point is sometimes irrelevant to another point. The vocabularies that I use are too monotonous.

\section{P4: D. I am a little bit confused in using the exact or proper vocabulary while speaking.}

Meanwhile, followings are participant's responses after having Knowledge Expansion and Feedback:

P3: E. The activities motivated me to study hard since I can recognize my own mistake. I also will be more careful about using grammar later. I will try to minimize filled pause such as saying eee.. eemm..

Furthermore, from the feedbacks, the participants stated that the treatments encouraged them to speak face to face spontaneously, and they said that even though they are in doubt about their capability to speak in a foreign language, at least their confidence is encouraged by these treatments. Another participant said that their speaking performance was not judged because they felt that in DA session did not focus on the level or the score they got, instead it was focused on the process of developing their potential. This is similar to Ningrat and Mayasari [46] who said that the essential point of learning is its process, not a score of the final result. In further explainations, they believed that if the process of learning and teaching works well, it will give more impact toward the result. Along DA session, the participants were given the reasonable strategies and knowledge to overcome their difficulties which based on their interest and needs. Providing knowledge expansion is very benificial for the participants' preparation in performing speech. They were inherently not afraid anymore since the process of speaking performance was prepared appropriatly. In this 
matter, the mediator gave clear introduction about performing speaking and some materals to the learners. The mediator also provided a well-organized procedure of performing speaking and provided the opportunity to the learners to correct themselves. As the result, it made the learners more responsible with their own mistakes without feeling judged by the mediator. The learners were more curious and enthusiastic to express or ask directly to their mediator of what they need and what they should do to reduce filled, reduce repetition, and retraced false start while speaking. In this way, the implementation of DA extremely encouraged learners' potential based on their ZPD. In other words, the enggagement could be more effective when the learners' potential orientation was in line with their ZPD in term of their needs, interest, self-regulation and ability [47].

\subsection{What are the learners' attitudes toward DA?}

After experiencing DA sessions, the participants reported their thought, experience, feeling, and attitude toward DA session in the semi-structured interviews. In the interviews, the participants had reported that while participating in the DA session, they felt more motivated to speak along the process. The quotation can be seen as follows:

P2: I. After finding out my improvement at particular part of speaking performance, this session enhances my willingness to practice more based on the steps provided

P3: E. When I know how to correct my mistakes step by step during the session, I feel encouraged to fixed the mistakes that I have found immediately and try to practice again for the better results.

Moreover, in Nazari [38] research which based on the reports found that DA was process-oriented and strongly emphasizes various and dynamic learning strategies. Most of the participants reported that they would be pleased if their speaking performance is encouraged through DA session. One participant also reported that DA session provided full self-improvement and evaluation rather than competition. So, this participant felt that their level of speaking performance would not be judged as a score contests. This participant also said that in DA session, they did not have to think about the other participants speaking performance, but rather focus on their performance and improvement. These matters can be seen as following quotations:

P2: I. I am pleased that I can choose any topics for my speaking practices in the session, and I am also triggered to practice my speaking when the mediator gave me clear example of how to speak well by demonstrating his speech before asking me to perform in the pretest and post-test session.

P1: N. The self-evaluations session gives me more space to explore my unidentified mistakes that I never relalized. I can learn how to analyzed, correct, and develop my speaking skill by myself through feedbacks and practices given.

P3: E. I can involve to make a simple correction for my mistakes through transcriptions provided and ask whatever the questions regarding the mistakes I have done in my speech. I feel comfortable that the assessment has no score and conducted one by one, it is more personal I think.

P4: D. I am relief that the sessions do not give the score for my speech. In this way, I can focus to practice and practice for myself. Sometimes, I feel down when my bad English speaking is scoring or judged as my final ability. So, I feel not be shy and be compared with other students in the session.

P4: D. The session teaches me how to think in sequence or with clear steps to deliver the speech. I thought that I got a lot of practices in this session in short time.

The above matters were in line with Shafiee, Talakoob, and Fatahi [47] who stated that the learners needed to feel free to practice their oral production in order to develop their accuracy. Therefore, they did not feel being compared or judged with the other participants regarding their speaking performance. The learners naturally needed a freedom in which synchronous with their self-orientation in learning. 
Furthermore, the self-evaluation and knowledge expension sessions was given not only to enhance the learners' understanding on their mistakes analysis, but also to enhance the assessor's unserstanding on learners' difficulties and problems that found during the session. The assesors gave full attention to their improvement matter and strategies for a better speaking performance in the future learning. In other words, assessing the potential of learners' learning means is encouraging their ZPD through mediation [47]. In this context, the individual asessment approach based on ZPD is DA [44]. Moreover, the participants were attracted with responsive feedback and centered interaction on their progress. So, they felt that they were not afraid anymore for making mistakes in speaking, and felt that their confidence was very encouraged.

Previously, some participants felt that they were afraid to deal with their mistakes in speaking. They frequently felt afraid of making mistakes in speech, felt afraid of the improper words and unorgonized sentences, felt embarrassed to make the same error, and felt embarrassed for making many filled pauseds while speaking. However, after experiencing intensive DA session, those participants felt more confident to speak whatever the topic was. Thus, they were not afraid or embarrassed anymore to perform, or without worrying being labeled or judged about how many mistakes or non-fluency they had done in DA sessions. All of these matters can be seen in following quotations:

P2: I. The session eased me to fix some errors in my speech because the corrections and feedbacks were given directly and immediately... I also can ask whatever the question related to my development.

P3: E. Previously, I do many filled pauseds and repetitions as I seen in the transcriptions and records of the pre-test. I also see that I often use double verb improperly. Recognizing these mistakes in the session give me immediate action to correct and minimize the nonfluency in my speech.

P1: N. I am always thinking in my mind that how if I make many mistakes in my speech? I am really afraid if my speaking ability is very bad especially in constructing the sentence in speech. The session serves me the opportunity to fix my mistakes and change my mind to not worry about being judged anymore while performing speech.

P1: N. After listening the records and reading the transcriptions of my speaking performance in the post-test, I can clearly listen and see my improvement in my speech. I see that I only make little mistakes in the transcriptions. My performance also more active and confidence as I have listened in the speaking records. I thought that I can manage my mistakes if the steps are clear.

P1: N. The given topics are interesting and have clear steps to explore it, it gives me willingness to talk about the it especially the optional topics and free topics.

P4: D. Previously, I am afraid of being labeled as a bad English speaker when having conversation about some topics. But, I feel relief when I can fix it and find out that my English speaking was improved as I read and listen in my speaking's transcriptions and speaking's records in the post-test stage.

Regarding labeling, Teo [6] believed that creating label to the learners will lead to negative paradigm that all low achiever learners remain low in their performance. Therefore, DA is a good alternative to improve learners' performance in English speaking. Besides, the result showed that DA clearly encouraged learners' confidence, motivation, and speaking abilities during the sessions. Many experts discussed about DA contributions toward learners' confidence and motivation as the result of self-evaluation, feedback, and self-orientation in DA mediation. For example, learners used their inner voice or self-orientation as primary principle in learning since it increased their self-confidence and decrease their anxiety [48]. The students obtained confidence and self-esteem when they find out some improvement in their language skills caused by DA [49]. The learners felt more less pressure and more learning advantage in DA where learners' performance increase significantly through maintaining good mediation in learning process compare with focusing on the score-orientation [38]. DA helped the learners to encourage themselves to believe in their own existing sources and improve their self-spontaneous or natural learning [33]. Due to the implementation of DA is very uncommon in Indonesia, the researchers were attracted to promote and explore the significant benifit and influence of DA toward Indonesian EFL learners through the research. 
In addition, one of participants had reported in interviews that DA session should be conducted consistently and with a well-structural session as part of teaching and learning process. This report showed participants' good-portrayal on DA session had increased positively. The result also showed that the more the participants participate in DA session, the more their expectation to improve themselves as they felt closer to a fluent lecturer. The participants also stated that it enabled them to recognize their own mistakes or error in speaking. All these findings showed strong learners' attitude toward the application of DA that can be seen in learners' positive reflection as following quotations:

\section{P3: E. I thought that this session should be applied as frequent as possible to get the better performance for my speech.}

\section{P4: D. This session provides me a lot of experience of how to recognize or identify my mistakes in performing speaking.}

P2: I. Many things I can learn in this session. First, I learn how to select the proper vocabulary in particular context. Second, I learn how to overcome my repetition during performing speaking. Third, I learn how to construct a well-speech structure with proper coherence among the paragraphs. Fourth, I learn how to get a fluency booster through body gesture in comfortable ways. So, this way helps me to minimize the non-fluency of my speech.

\section{P2: I. I have a chance to learn about making an analysis on my speaking ability through the records and speaking's transcriptions.}

P1: N. Personally, I thought that this session can be used by my lecturers to get deeper identification on their students' development and improvement in speaking skill. Even it is useful for lecturers to recognize their students' characteristics and learning style.

From all the reports above, it showed how intensive the expectation of participants toward DA effect on their performance. Regarding the positive attitude reflected by participants, the study also supported several other related studies, which was discussing about how the learners behave and thought toward DA principles in the different topics. Yakisik and Cakir [49]; Jarrahzadeh and Tabatabaei [50]; Ebadi and Asakareh [33]; Karimi and Shafiee [34]; Amirsheibani, Tamri, and Moghaddam [51]; and Shafiee et al. [47] were exploring how the learners behave toward DA practice in the classroom. The discussions showed that participants respond positively and agreed with DA application since it motivated and focused on the process of their development especially in exploring and correcting their own deeper weaknesses. Even, it also provided intensive feedback in accordance with learners' orientation. Besides, it also supports collaborative learning not only in the classroom context but also in wider learning environment [52]

The investigation also showed the implication of the research in the practicality and its implementation in Indonesian context. As the researchers' investigation, it was very few research concerning DA implementation in Indonesia especially university EFL learners. Even, the research concerning DA in other countries is also scarce. As Nazari [21], Vafaee [53], and Karimi and Shafiee [34] argued that DA research is still scarce or not emprically implemented, the stage could be said at embryonic level. Therefore, more continuous research needs to be conducted to reveal its contribution toward educational assessment concerns.

\section{CONCLUSION}

The research explored the Dynamic Assessment's effect on Indonesian university EFL learners who have faced difficulties, especially in performing English speaking. This study is very significant to be concerned since there was no significant attempt of speaking class in Indonesia to apply DA for EFL learners at a previous time. The result showed that DA significantly facilitates participants to improve their speaking performance. The participants showed that they boosted their inner self-esteem on their speaking performance and showed their attention to their improvement. Moreover, this statement was supported by some evidences taken from participants' self-evaluation and feedback. Participants strongly stated that DA session can be their learning platform in improving their speaking performance.

Furthermore, the participants actively involved in the test during DA session which showed DA session encouraged them to concern on their progress in speaking. The participants looked like more engaged with DA session, which was proven by their body gestures; most of them moved their hand and raised their 
voice purposively while performing their idea in speaking. Each participant performed in various ways in achieving the best performance without realizing that their performances were judged since they recognized that they had opportunities to evaluate themselves and gain motivation and feedback during DA session. The participants also felt their progress was directed step by step structurally. From the DA and report from the interviews, it showed that the participants maintained a positive attitude toward DA. The participants showed that they developed themselves to be engaged, self-directed, motivated, and activated purposively toward doing the test, while accepting feedback, knowledge expansion and self-evaluation. Thus, it makes clear evidence that DA is potential and essential to be applied in a classroom, especially for low level and less confident learners.

The researchers recommend that educators should not underestimate the learners with low speaking quality because they are still finding the right or the exact learning strategies and still in the process of developing self-confidence. The educators are expected to not focus on the judgment through scores which make learners feel being judged and uncomfortable during their on-going development. The focus should be given to the efforts to encourage them to speak comfortably and without feeling intimidated.

\section{REFERENCES}

[1] Pratolo, B. W., "Exploring Indonesian Learners' Beliefs about Language Learning Strategies through Reflection," Figshare. Doctoral Thesis, Monash University, Clayton, Australia, 2017. [Online]. Available: http://www.adb.org/sites/default/files/publication/159308/adbi-financial-inclusion-asia.pdf

[2] Ramdani, J. M. and Rahmat, "Promoting speaking spontaneity in large classes: An action research approach in an Indonesia EFL setting," Indonesian Journal of Applied Linguistics, vol. 8, no. 2, pp. 388-401, 2018.

[3] Cowen J., "Designing assessment to enhance student learning," 2005. [Online] Available: http://www.heacademy.ac.uk/assets/ps/documents/practice_guides/practice_guides/ps0069_designing_assessment_ to_improve_physical_sciences_learning_march_2009.pdf

[4] Sternberg, R. J., Grigorenko, E. L., Birney, D. P., Fredine, N., Jarvin, L., and Jeltova, I., "Dynamic instruction for and assessment of developing expertise in four ethnic groups," (RM07226). Storrs: University of Connecticut, The National Research Center on the Gifted and Talented, 2007.

[5] Hasim, Z., Di, S., and Barnard, R., "Eliciting teachers' understanding and their reported practices on school-based formative assessment: Methodological challenges," Indonesian Journal of Applied Linguistics, vol. 8, no. 1, pp. 158-166, 2018.

[6] Teo, T. W., "Broadening and deepening the dialogue about low achievers," Asia Pacific Journal of Education, vol. 38, no. 3, pp. 275-278, 2018.

[7] Kozulin, A, Mediated learning experience and cultural diversity. Unlocking The Human Potential Conference (August 18-20, 2001), Royal Crown Conference Centre, Winnipeg, 2001.

[8] Tzuriel, D., "Dynamic assessment of young children: Educational and intervention perspectives," Educational Psychology Review, vol. 12, no. 4, pp. 385-435, 2000.

[9] Race, P., Brown, S., and Smith, B., 500 Tips on assessment: 2nd edition, London: Routledge, 2005.

[10] Tangdhanakanond, K., "Authentic assessment," Journal of the Faculty of Education Chulalongkorn University, vol. 34, no. 3, pp. 1-13, 2006.

[11] National Research Council, National Science Education Standards. Washington. DC: National Academy Press, 1996.

[12] Dochy, F., "A new assessment era: different needs, new challenges," Research Dialogue in Learning and Instruction, vol. 10, no. 1, pp. 11-20, 2001.

[13] Luoma, S., Assessing speaking. Cambridge, UK: Cambridge University Press, 2004.

[14] Sternberg, R. J., Prologue. In C. S. Lidz and J. G. Elliot (Eds.), Dynamic assessment: Prevailing models and applications. Amsterdam: JAI, 2000.

[15] Dorfler, T., Golke, S., and Artelt, C., "Dynamic assessment and its potential for the assessment of reading competence," Studies in Educational Evaluation, vol. 35, no. 2, pp. 77-82, 2009

[16] Leung, C., "Dynamic assessment: Assessment for and as teaching?" Language Assessment Quarterly, vol. 4, no. 3 , pp. 257-278, 2007.

[17] Poehner, M. E. and Lantolf, J. P., "Vygotsky's teaching-assessment dialectic and L2 education: The case for dynamic assessment," Mind, Culture, and Activity, vol. 17, no. 4, pp. 312-330, 2010.

[18] Lantolf, J. P. and Poehner, M. E., "Dynamic assessment in the classroom: Vygotskian praxis for second language development," Language Teaching Research, vol. 15, no. 1, pp. 11-33, 2011

[19] Roehr, K. and Ganem-Gutiérrez, G. A., The metalinguistic dimension in instructed second language learning. London: Bloomsbury, 2013.

[20] Heritage, M., et al., English language learners and the newstandards: Developing language, content knowledge, and analytical practices inthe classroom. Cambridge, MA: Harvard Education Press, 2015.

[21] Nazari, B., "Teach-to-test instruction of dynamic assessment: A critical overview," Bellaterra Journal of Teaching and Learning Language and Literature, vol. 5, no. 4, pp. 56-68, 2012.

[22] Baek, S.-G and Kyoung, J. K., "The effect of dynamic assessment based instruction on children's learning," Asia Pacific Education Review, vol. 4, no. 2, pp. 189-198, 2003. 
[23] Haywood, H. C., and Lidz, C. S., Dynamic assessment in practice: Clinical and educational applications. Cambridge: Cambridge University Press, 2006.

[24] VanderVeen, C., Dobber, M., and van Oers, B., "Implementing dynamic assessment of vocabulary development as a trialogical learning process: A practice of Evaluator support in primary education schools," Language Assessment Quarterly, vol. 13, no. 4, pp. 329-340, 2016.

[25] Mehri, E. and Amerian, M., "Challenges to dynamic assessment in second language learning," Theory and Practice in Language Studies, vol. 5, no. 7, pp. 1458-1466, 2015.

[26] Poehner, M. E., "Dynamic assessment of oral proficiency among advanced L2 learners of French," Unpublished doctoral dissertation, Pennsylvania State University, Pennsylvania, 2005.

[27] Weir, C. J., Language testing and validation: An evidence-based approach. Basingstoke: Palgrave Macmillan, 2005.

[28] Murphy, R., Dynamic assessment, intelligence, and measurement. Chichester, West Sussex: Wiley-Blackwell, 2011.

[29] Lauchlan, F., "Improving learning through dynamic assessment," The Australian Educational and Developmental Psychologist, vol. 29, no. 02, pp. 95-106, 2012.

[30] Underhill, N., Testing spoken language: A handbook of oral testing techniques. Cambridge: Cambridge University Press, 1987.

[31] O’Sullivan, B., "Towards a model of performance in oral language testing," Unpublished Ph.D. thesis, University of Reading, Reading, UK, 2000.

[32] Khoshsima, H. and Farokhipours, S., "On the role of different models of dynamic assessment on promoting speaking," International Journal of Humanities and Cultural Studies, vol. 2, no. 4, pp. 586-600, 2016.

[33] Ebadi, S. and Asakereh, A., "Developing EFL Learners' Speaking Skills through Dynamic Assessment: A Case of A Beginner and An Advanced Learner," Cogent Education, vol. 4, no. 1, pp. 1-18, 2017.

[34] Karimi, M. N. and Shafiee, Z., "Iranian EFL teacher's perceptions of dynamic assessment: exploring the role of education and length of service," Australian Journal of Teacher Education, vol. 39, no. 8, pp. 143-162, 2014.

[35] Cresswell, J.W., Research design: Qualitative, quantitative, and mixed method approaches (4th ed.). London: SAGE, 2014.

[36] Punch, K. F. and Oancea, A., Introduction to Research Methods in Education (2nd ed). Los Angeles and London: SAGE, 2014.

[37] Cohen, L., et al., Research Method in Education (7th ed). London and New York: Routledge Falmer, 2011.

[38] Nazari, A., "Dynamic assessment in higher education English language classes: a lecturer perspective," The Journal of Language Teaching and Learning, vol. 7, no. 1, pp. 100-118, 2017.

[39] Pratolo, B. W., "How Would Our Students Like to Be Corrected? A Study on Learners' Beliefs about Language Learning Strategy," Humanities \& Social Sciences Reviews, vol. 7, no. 3, pp. 274-281, 2019.

[40] Mitchell, R., et al., Second language learning theories (3rd ed). London and New York: Routledge, 2013.

[41] Vygotsky, L., Mind in Society. USA: Harvard College, 1978.

[42] Lantolf, J. P. and Poehner, M. E., "Dynamic assessment of L2 development: bringing the past into the future," Journal of Applied Linguistics, vol. 1, no. 1, pp. 49-72. 2004.

[43] Nasir, C., Yusuf, Y. Q., and Wardana, A., "A qualitative study of teacher talk in an EFL classroom interaction in Aceh Tengah, Indonesia," Indonesian Journal of Applied Linguistics, vol. 8, no. 3, pp. 525-535, 2019.

[44] Lidz, C. S. and Pena, E. D., "Response to intervention and dynamic assessment: Do we just appear to be speaking the same language?" Seminars in Speech and Language, vol. 30, no. 2, pp. 121-133, 2009.

[45] Sun, S. G. and Wen, Q. F., "Teacher-student collaborative assessment (TSCA) in integrated language classrooms," Indonesian Journal of Applied Linguistics, vol. 8, no. 2, pp. 369-379, 2018.

[46] Ningrat, H. C. and Mayasari, L., "The effectiveness of using Webtoons to develop students' speaking performance on recount," Humanities \& Social Sciences Reviews, vol. 7, no. 3, pp. 472-476, 2019.

[47] Shafiee, S., et al., "Effects of dynamic assessment on the acquisition of the rhythm of English: the case of EFL learners' attitudes," International Journal of English Linguistics, vol. 8, no. 5, pp. 181-191, 2018.

[48] Tomlinson, B., "The inner voice: A critical factor in L2 learning," The Journal of the Imajination in Language Learning and Teaching, vol. 6, 2001.

[49] Yakisik, B. Y. and Cakir, A., "Dynamic assessment of prospective English teachers' speaking skills," European Journal of English Language Teaching, vol. 2, no. 1, pp. 22-49, 2017.

[50] Jarrahzadeh, Z. and Tabatabaei, O., "Gender based study of learners' reading through dynamic assessment (DA): Guthke's Learntest approach in focus," International Journal of Foreign Language Teaching and Research, vol. 2, no. 7, pp. 47-53, 2014.

[51] Amirsheibani, M., Tamri, M. S., and Moghadam, S. Y., "Dynamic assessment of Iranian EFL learners' writing ability," The Iranian EFL Journal, vol. 10, no. 3, pp. 143-161, 2014.

[52] Arta, B. Multiple Studies: The Influence of Collaborative Learning Approach on Indonesian Secondary High School Students' English-Speaking Skills. English Language Teaching Educational Journal, vol. 1, no. 3, pp. 149-160, 2019.

[53] Vafaee, P., "Dynamic assessment: A dialetical integration of assesssment and instruction," Teachers College, Columbia University Working Papers in TESOL and Applied Linguistics, vol. 11, no. 1, pp. 63-66, 2011. 